\title{
PENGARUH SERVICE, CLEANLINESS, ORGANIZATION, DAN HEALTHINESS TERHADAP QUALITY PADA RESTORAN DI JAKARTA
}

\author{
DENNY SEPTA HARYANTI \\ NUNO SUTRISNO \\ LYVIA \\ Sekolah Tinggi IImu Ekonomi Trisakti, Jl. Kyai Tapa No.20, Jakarta, Indonesia \\ rutlyvia@yahoo.com
}

\begin{abstract}
The purpose of this study is to determine the effect of service, cleanliness, organization, and healthiness to quality of sushi tei restaurant in DKI Jakarta. The design of this study using descriptive research and causality research, the measurement of each variable using 5 points Likert scale. This study uses primary data and data collection through questionnaires. The research sample was obtained through a purposive sampling method and obtained as many as 145 respondents. The results of this study show that Organization has no effect to Quality, while Service, Cleanliness, and Healthiness have an influence to Quality.
\end{abstract}

Keywords: Service, cleanliness, organization, healthiness, quality

Abstrak: Tujuan penelitian adalah untuk mengetahui pengaruh layanan, kebersihan, organisasi dan kesehatan terhadap kualitas pada restoran sushi tei di DKI Jakarta. Rancangan penelitian ini menggunakan penelitian deskriptif dan penelitian kausalitas, pengukuran setiap variabel menggunakan 5 poin skala Likert. Penelitian ini menggunakan data primer dan pengumpulan data melalui kuesioner. Sampel penelitian diperoleh melalui metode purposive sampling dan memperoleh sebanyak 145 responden. Hasil dari penelitian ini menunjukan bahwa organisasi tidak memiliki pengaruh terhadap kualitas, sedangkan layanan, kebersihan dan kesehatan memiliki pengaruh terhadap kualitas.

Kata kunci: Layanan, kebersihan, organisasi, kesehatan, kualitas

\section{PENDAHULUAN}

Perkembangan persaingan dalam
industri makanan yang disebabkan oleh
globalisasi sekarang semakin kompetitif dalam
berbisnis. Hal ini terjadi karena banyak pesaing
bisnis yang membuka usaha di industri
makanan lokal yang sama. Selain itu
globalisasi adalah sebuah proses dimana
terjadi pertukaran dalam industri makanan
diantara Indonesia dengan negara lain. Oleh
karena itu, banyak pesaing bisnis yang

membuka usaha di industri makanan yang berasal dari luar Indonesia yang ikut meramaikan bisnis di Indonesia. Tidak sedikit dari masyarakat yang mengikuti setiap perubahan kecil yang telah terjadi yang disebabkan oleh globalisasi.

Selain globalisasi yang menyebabkan persaingan, perubahan gaya hidup seseorang dalam mengkonsumsi makanan saat ini juga didorong dari terjadinya globalisasi di Indonesia. Seperti kegiatan makan yang pada awalnya dilakukan untuk memenuhi kebutuhan 
hidup setiap masyarakat, namun pada zaman modern ini banyak masyarakat yang ingin mengkonsumsi makanan yang tidak hanya dari Indonesia saja, tapi dari luar Indonesia juga. Untuk memenuhi keinginan masyarakat untuk mencoba makanan yang berasal dari luar Indonesia, bisnis di industri makanan menjadi hal yang menjanjikan.

Salah satu industri makanan yang muncul dari adanya globalisasi yang terjadi di Indonesia adalah sushi. Sushi merupakan salah satu makanan yang berasal dari Jepang yang sering dicari dan digemari oleh masyarakat Indonesia. Karena keunikan dari sushi, banyak masyarakat yang memilih sushi sebagai makanan kesukaan mereka dan tidak sedikit dari masyarakat yang sering mengunjungi restoran sushi untuk menikmatinya sehingga popularitas pada makanan sushi menjadi sangat luas. Peluang yang muncul dari kegemaran masyarakat pada sushi, membuat pengusaha mengambil kesempatan tersebut untuk membuka usaha, termasuk usaha restoran sushi yang ramai di kalangan masyarakat. Usaha restoran sushi akan sangat menguntungkan jika dikelola dengan baik. Oleh sebab itu, banyak restoran sushi yang dapat ditemui di Indonesia yang didirikan oleh orang asing atau orang Indonesia sendiri.

Berdasarkan data dari Top Brand Index, terdapat banyak restoran sushi yang sering dikunjungi oleh masyarakat seperti Sushi Tei, Ichiban Sushi, Sushi Miyabi, Sushi Groove, D'Sushi Bodo, dan lainnya, dimana setiap restoran menyajikan macam-macam sushi yang berbeda dan memiliki kelebihan hingga kekurangan masing-masing.

Dari data Top brand Index tersebut dapat dilihat bahwa untuk restoran sushi, Sushi Tei menempati posisi pertama dari data Top Brand Index yang menggambarkan bahwa Sushi Tei menguasai pangsa pasar. Namun karena semakin berkembangnya industri restoran sushi di Indonesia, menciptakan persaingan yang semakin ketat dalam industri restoran sushi tersebut. Seperti yang ada di Top Brand Index diatas, restoran Ichiban Suhi mengalami kenaikan yang konsisten pada tahun 2016 sampai 2018 hingga mencapai $27,4 \%$ berdasarkan Top Brand Index. Hal tersebut mengkhawatirkan karena Sushi Tei sebagai penguasa pangsa pasar, posisinya dapat diambil alih oleh Ichiban Sushi. Hal tersebut membuktikan bahwa Sushi Tei sebagai penguasa pangsa pasar masih belum aman pada posisinya. Belum lagi banyaknya restoran sushi yang baru masuk ke Indonesia. Sushi Tei sendiri masuk ke Indonesia pada tahun 2003. Masih banyak restoran sushi lain yang bermunculan di Indonesia seperti Kiyadon Sushi pada tahun 2007. Pada tahun 2014 juga ada restoran sushi yang baru berdiri di Indonesia seperti 3 Wise Monkeys dan Genki Sushi. Restoran sushi Sushi Hiro yang cukup terkenal belakangan ini berdiri pada tahun 2016, dan masih banyak lagi restoran sushi lainnya.

Kondisi persaingan yang semakin ketat di antara restoran sushi yang digambarkan oleh Top Brand Index serta munculnya beberapa restoran sushi di Indonesia harus menjadi perhatian restoran sushi terutama Sushi Tei yang menjadi objek penelitian ini untuk meningkatkan daya saingnya agar terus dapat bertahan di industri restoran sushi. Salah satu strategi yang dapat diterapkan oleh restoran sushi terutama Sushi Tei dengan cara meningkatkan kualitas makanan. Quality sendiri merupakan kemampuan sebuah produk atau jasa untuk secara andal melakukan apa yang seharusnya dilakukan dan untuk memenuhi harapan pelanggan (Robbins dan Coutler, $2018,693)$. Kualitas makanan yang baik dapat meningkatkan kualitas yang dirasakan oleh pelanggan setelah mencoba makanan tersebut dan dapat memenuhi harapan pelanggan terhadap makanan tersebut. Kualitas dari makanan yang baik akan memengaruhi daya saing yang berkelanjutan pada sebuah restoran 
dalam persaingan di industri restoran. Hal ini didukung oleh Robbins dan Coutler $(2018,324)$ mengungkapkan bahwa jika kualitas diterapkan dengan baik, kualitas dapat menjadi sebuah cara untuk menciptakan daya saing yang berkelanjutan dan dapat memisahkan diri dari pesaing lainnya. Berdasarkan penelitian yang dilakukan Rogerio Scabim Morano, Alcides Barrichelo, Rafael Ricardo Jacomossi dan Jorge Ramon D'Acosta-Rivera (2018) mengungkapkan bahwa Service, Cleanliness, Organization, dan Healthiness mempunyai pengaruh terhadap Quality.

\section{Quality}

Heizer (2017, 255) mendefinisikan quality adalah kemampuan dari sebuah produk untuk memenuhi kebutuhan pelanggan. Robbins dan Coulter (2018, 693) mendefinisikan quality adalah kemampuan dari sebuah produk atau jasa untuk untuk secara andal melakukan apa yang seharusnya dilakukan dan untuk memenuhi harapan pelanggan.Tinoco dan Ribeiro (2008) dalam Morano (2018) mendefnisikan quality adalah hasil dari perbandingan antara harapan pelanggan dan kinerja yang dirasakan.

\section{Service}

Menurut Kotler dan Keller $(2016,422)$ Service merupakan tindakan atau kinerja apa pun yang dapat ditawarkan satu pihak kepada pihak lain yang pada dasarnya tidak berwujud dan tidak mengakibatkan kepemilikan apa pun. Restoran tidak hanya menyediakan makanan untuk dirasakan oleh pelanggan, melainkan layanan yang baik juga akan dirasakan oleh pelanggan. Karena bagi pelanggan, pelayanan yang baik yang mereka terima dari restoran akan berpengaruh terhadap kualitas yang pelanggan rasakan selain makanan yang sesuai dengan harapan pelanggan yang dapat dilihat dari beberapa hal pada pekerja seperti kebersihan ketika melayani, tingkah laku yang sopan dan perhatian yang maksimal pada pelanggan. Hal ini juga didukung oleh Morano et al. (2018) mengungkapkan bahwa terdapat pengaruh positif dari layanan ke kualitas maka penting untuk menerapkan tingkah laku yang sopan, perhatian yang maksimal dari pekerja, dan kebersihan pada pekerja di restoran kepada pelanggan.

$\mathrm{H}_{1}$ : Terdapat pengaruh service terhadap quality.

\section{Cleanliness}

Menurut Barber (2010) Cleanliness merupakan komponen penting dari keseluruhan lingkungan fisik dan memberikan pengaruh penilaian pelanggan terhadap pengalaman layanan. Restoran menyediakan makanan untuk dinikmati oleh pelanggan dan kebersihan pada restoran tersebut juga merupakan faktor penentuan kualitas bagi konsumen. Karena restoran, alat makan, dan lingkungan restoran yang bersih akan membuat konsumen merasa nyaman dan yakin pada kualitas yang ditetapkan oleh mereka kepada restoran. Hal ini juga didukung oleh Saha et al., (1989) mengungkapkan bahwa kebersihan memiliki hubungan secara langsung kepada kualitas yang dapat dilihat dari bagaimana pekerja menjaga, merawat, dan membersihkan lingkungan.

$\mathrm{H}_{2}$ : Terdapat pengaruh cleanliness terhadap quality.

\section{Organization}

Menurut Bateman (2017) Organizing merupakan fungsi manajemen mengumpulkan dan mengoordinasikan sumber daya manusia, keuangan, fisik, informasi, dan lainnya yang diperlukan untuk mencapai tujuan. Pengorganisasian merupakan aktivitas yang dilakukan oleh organisasi. Pengorganisasian yang dapat dilakukan pada restoran agar dapat memiliki organisasi yang baik dapat melalui memberikan produk modifikasi yang baik, hubungan antara gerai yang baik, suasana lokasi gerai yang baik, dan komplementaritas produksi dan kapasitas dengan gerai yang lain. Hal tersebut dilakukan untuk meningkatkan 
kualitas yang ditetapkan oleh pelanggan terhadap restoran yang didatangi oleh mereka. Hal ini juga didukung oleh penelitian Walsh et al. (2014) mengungkapkan bahwa produk modifikasi, hubungan antara gerai, suasana lokasi gerai, dan komplementaritas produksi dan kapasitas dengan gerai lain yang ada di sekitar lokasi dapat meningkatkan kualitas yang dirasakan oleh pelanggan.

$\mathrm{H}_{3}$ : Terdapat pengaruh organization terhadap quality.

\section{Healthiness}

Menurut Mai (2016) Healthiness merupakan harapan tentang manfaat kesehatan suatu produk dan pengaruh produk pada kondisi kesehatan seseorang. Banyak masyarakat yang menginginkan makanan yang sehat. Cara yang dapat dilakukan untuk restoran agar dapat membuat makanan yang sehat, yaitu dengan menggunakan bahan baku yang segar, sehat, bersih, dan higienis. Karena makanan yang sehat dapat meningkatkan kualitas yang ditetapkan oleh pelanggan terhadap restoran. Penelitian ini juga didukung oleh Morano et al. (2018) mengungkapkan bahwa terdapat pengaruh positif dari kesehatan ke kualitas dan saling berhubungan karena ketika kesehatan pada makanan baik, maka kualitas juga akan baik. Oleh sebab itu, kesehatan merupakan hal yang penting terhadap kualitas.

$\mathrm{H}_{4}$ : Terdapat pengaruh healthiness terhadap quality.

\section{METODE PENELITIAN}

Teknik pengambilan sampel digunakan dalam penelitian ini adalah non-probability sampling yaitu metode purposive sampling. Menurut Sugiyono (2016) purposive sampling didefinisikan sebagai "Teknik penentuan sampel dengan pertimbangan tertentu." Pengumpulan data dengan membagikan kuesioner di depan restoran Sushi Tei yang memiliki 13 gerai yang terletak di 13 mall yang berbeda di DKI Jakarta. Kriteria responden yang dapat digunakan di penilitan ini sebagai berikut (1) Konsumen yang merupakan pelanggan Sushi Tei yang mengkonsumsi dan melakukan transaksi minimal satu kali dalam satu bulan; (2) Konsumen yang berdomisili di DKI Jakarta.

Jumlah sampel yang diambil oleh peneliti sebanyak 145 responden. Hal ini sesuai dengan ketentuan Hair et al. (2014) yang menjelaskan "the researcher generally would not factor analyze a sample of fewer than 50 observation and preferably the sample size should be 100 or large." Penelitian menggunakan Analisis Regresi Berganda dengan pengolahan data menggunakan SPSS statistik 19. Analisis regresi berganda menurut Anderson et al. $(2014,684)$ adalah "The equation that describes how the dependent variable $y$ is related to the independent variables $X_{1}, X_{2}, \ldots \ldots X_{P}$ and an error term. Persamaan regresi menurut Anderson et al. (2014):

\section{HASIL PENELITIAN}

Berikut adalah hasil penelitian yang didapatkan dari data yang telah diolah:

Tabel 1 Jenis Kelamin Responden

\begin{tabular}{llllll}
\hline & & & & & Cumulative \\
& & Frequency & Percent & Valid Percent & Percent \\
\hline Valid & Wanita & 57 & 39,3 & 39,3 & 39,3 \\
& Pria & 88 & 60,7 & 60,7 & 100,0 \\
& Total & 145 & 100,0 & 100,0 & \\
\hline
\end{tabular}

Sumber: Pengolahan data SPSS 
Pada tabel dan gambar 1 terlihat bahwa jumlah responden berdasarkan jenis kelamin terdapat jumlah wanita lebih banyak dengan sebanyak 88 orang atau sebesar $60,7 \%$, sedangkan untuk jumlah jenis kelamin laki-laki sebanyak 57 orang atau sebesar $39,3 \%$. Kesimpulan yang dapat ditarik dari data tersebut adalah pelanggan restoran Sushi Tei di DKI Jakarta lebih banyak wanita dengan presentase $60,7 \%$. Dalam hal ini Sushi Tei dapat membuat strategi untuk menarik pelanggan Sushi Tei seperti melakukan promo spesial untuk pria pada restoran Sushi Tei, misalnya memberikan potongan harga pada International Men's Day pada 19 November.

Tabel 2 Usia Responden

\begin{tabular}{llllll}
\hline & & & & & Cumulative \\
& & Frequency & Percent & Valid Percent & $\begin{array}{l}\text { Percent } \\
\text { Valid }\end{array}$ \\
& $20-25$ & 51 & 35,2 & 35,2 & 35,2 \\
& $26-30$ & 55 & 37,9 & 37,9 & 73,1 \\
& $31-35$ & 24 & 16,6 & 16,6 & 89,7 \\
& $36-40$ & 13 & 9,0 & 9,0 & 98,7 \\
& $\geq 41$ & 2 & 1,4 & 1,4 & 100,0 \\
& Total & 145 & 100,0 & 100,0 & \\
\hline
\end{tabular}

Sumber: pengolahan data SPSS

Pada tabel dan gambar 2 terlihat bahwa jumlah responden berdasarkan usia. Responden yang berusia 20 - 25 tahun berjumlah 51 orang atau sebesar $35,2 \%$, responden yang berusia 26-30 tahun berjumlah 55 orang atau sebesar 37,9\%, responden yang berusia 31-35 tahun berjumlah 24 orang atau sebesar 16,6\%, responden yang berusia 36-40 tahun berjumlah 13 orang atau sebesar $9,0 \%$, dan responden yang berusia $\geq 41$ tahun berjumlah 2 orang atau sebesar $1,4 \%$. Berdasarkan data tersebut menunjukan bahwa Sushi Tei memiliki pelanggan terbanyak yang berusia diantara 2630 tahun sebesar $37,9 \%$, sehingga Sushi Tei dapat mengetahui target pasarnya dan dapat menentukan strategi yang tepat untuk melakukan promosi seperti memberikan promosi dengan memberikan voucher potongan harga dan melakukan berbagai promo lainnya agar dapat menarik semua kalangan usia untuk menjadi pelanggan Sushi Tei.

Tabel 3 Pendapatan Responden

\begin{tabular}{lrccc}
\hline & Frequency & Percent & $\begin{array}{c}\text { Valid } \\
\text { Percent }\end{array}$ & $\begin{array}{c}\text { Cumulative } \\
\text { Percent }\end{array}$ \\
\hline Valid $\leq$ Rp 5.000.000 & 20 & 13,8 & 13,8 & 13,8 \\
Rp 5.000.000-Rp 10.000.000 & 61 & 42,1 & 42,1 & 55,9 \\
Rp 10.000.000-Rp 15.000.000 & 43 & 29,7 & 29,7 & 85,6 \\
I Rp 15.000.000 & 21 & 14,5 & 14,5 & 100,0 \\
Total & 130 & 100,0 & 100,0 & \\
\hline
\end{tabular}

Sumber: pengolahan data SPSS

Pada tabel dan gambar 3 dapat dilihat mengenai jumlah responden berdasarkan pendapatan. Jumlah responden yang memiliki pendapatan sebesar $\leq R p 5.000 .000$ berjumlah 
20 orang atau sebesar 13,8\%, jumlah responden yang memiliki pendapatan sebesar Rp 5.000.000 - Rp 10.000.000 berjumlah 61 orang atau $42,1 \%$, responden yang memiliki pendapatan sebesar Rp 10.000.000 - Rp 15.000.000 berjumlah 43 orang atau sebesar $29,7 \%$, dan responden yang memiliki pendapatan sebesar $\geq$ Rp 15.000.000 berjumlah 21 orang atau sebesar 14,5\%.
Berdasarkan data tersebut menunjukan bahwa pelanggan Sushi Tei di DKI Jakarta sebagian besar memiliki pendapatan sebesar Rp 5.000.000 - Rp 10.000.000, untuk itu agar pelanggan Sushi Tei terus meningkat, Sushi Tei dapat melakukan strategi dengan memberikan lebih banyak diskon atau potongan harga agar banyak pelanggan dapat lebih sering menikmati Sushi Tei.

Tabel 4 Hasil Uji Validitas

\begin{tabular}{|c|c|c|c|c|}
\hline Variabel & $\begin{array}{c}\text { Item } \\
\text { Pertanyaan }\end{array}$ & r hitung & $\begin{array}{c}r \text { tabel } \\
(d f=n-2)\end{array}$ & Keterangan \\
\hline \multirow[t]{3}{*}{ Service $\left(X_{1}\right)$} & SER 1 & 868 & 0,1631 & Valid \\
\hline & SER 2 & 863 & 0,1631 & Valid \\
\hline & SER 3 & 831 & 0,1631 & Valid \\
\hline \multirow[t]{3}{*}{ Cleanliness $\left(\mathrm{X}_{2}\right)$} & CLN 1 & ,883 & 0,1631 & Valid \\
\hline & CLN 2 & ,859 & 0,1631 & Valid \\
\hline & CLN 3 & ,842 & 0,1631 & Valid \\
\hline \multirow[t]{3}{*}{ Organization $\left(\mathrm{X}_{3}\right)$} & ORG 1 & ,862 & 0,1631 & Valid \\
\hline & ORG 2 & 853 & 0,1631 & Valid \\
\hline & ORG 3 & 857 & 0,1631 & Valid \\
\hline \multirow[t]{3}{*}{ Healthiness $\left(X_{4}\right)$} & HLT 1 & 825 & 0,1631 & Valid \\
\hline & HLT 2 & 860 & 0,1631 & Valid \\
\hline & HLT 3 & 862 & 0,1631 & Valid \\
\hline \multirow[t]{3}{*}{ Quality (Y) } & QTY 1 & 892 & 0,1631 & Valid \\
\hline & QTY2 & ,914 & 0,1631 & Valid \\
\hline & QTY3 & 842 & 0,1631 & Valid \\
\hline
\end{tabular}

Sumber: pengolahan data SPSS

Berdasarkan dari tabel 4 dapat dilihat bahwa semua variabel independen (service, cleanliness, organization, dan healthiness) dan variabel dependen (quality) mempunyai nilai $r$ hitung lebih besar daripada $r$ tabel, kesimpulan yang dapat ditarik adalah setiap pertanyaan yang ada didalam kuesioner dinyatakan valid karena dapat mengukur apa yang seharusnya diukur.

Tabel 5 Hasil Uji Reliabilitas

\begin{tabular}{ccccc}
\hline Variabel & Pertanyaan & Cronbach Alpha & Batas $\mathbf{= 0 , 6 0}$ & Keterangan \\
\hline Service $\left(\mathrm{X}_{1}\right)$ & 3 & 0,815 & 0,60 & Reliabel \\
Cleanliness $\left(\mathrm{X}_{2}\right)$ & 3 & 0,826 & 0,60 & Reliabel \\
Organization $\left(\mathrm{X}_{3}\right)$ & 3 & 0,819 & 0,60 & Reliabel \\
Healthiness $\left(\mathrm{X}_{4}\right)$ & 3 & 0,806 & 0,60 & Reliabel \\
Quality $(\mathrm{Y})$ & 3 & 0,859 & 0,60 & Reliabel \\
\hline
\end{tabular}

Sumber: pengolahan data SPSS 
Tabel 6 Hasil Uji Hipotesis

\begin{tabular}{cccccc}
\hline \multicolumn{7}{c}{$\begin{array}{c}\text { Unstadardized } \\
\text { Coefficients } \\
\text { Model }\end{array}$} & B & Std. Error & $\begin{array}{l}\text { Standardized } \\
\text { Coefficients } \\
\text { Beta }\end{array}$ & t & Sig. \\
\hline 1 (Constant) & 1,152 &, 603 & & 1,912 &, 058 \\
X1 &, 247 &, 088 &, 242 & 2,823 &, 005 \\
X2 &, 370 &, 093 &, 381 & 3,994 &, 000 \\
X3 &, 126 &, 096 &, 129 & 1,310 &, 192 \\
X4 &, 166 &, 073 &, 166 & 2,284 &, 024 \\
\hline
\end{tabular}

Sumber: pengolahan data SPSS

Tabel 6 menunjukkan bahwa $\operatorname{Sig} \mathrm{X}_{1}$ sebesar 0,005 dan a sebesar 0,05 . nilai $p$-value $(0,005)<a(0,05)$ artinya terdapat pengaruh service terhadap quality pada Restoran Sushi Tei di DKI Jakarta. Nilai Sig $X_{2}$ sebesar 0,000 dan a sebesar 0,05 . Maka nilai $p$-value $(0,000)$ $<$ a $(0,05)$ dapat disumpulkan terdapat pengaruh cleanliness terhadap quality Restoran Sushi Tei di DKI Jakarta. Nilai Sig $\mathrm{X}_{3}$ sebesar 0,192 dan a sebesar 0,05 . Maka nilai $p$-value $(0,192)>$ a $(0,05)$ dapat disumpulkan tidak terdapat pengaruh organization terhadap quality pada Restoran Sushi Tei di DKI Jakarta. Nilai Sig $\mathrm{X}_{4}$ sebesar 0,024 dan a sebesar 0,05. Maka nilai $p$-value $(0,024)<a(0,05)$ dapat disumpulkan terdapat pengaruh Healthiness terhadap quality pada Restoran Sushi Tei di DKI Jakarta.

\section{PENUTUP}

Berdasarkan hasil analisis serta pembahasan mengenai pengaruh service, cleanliness, organization, dan healthiness terhadap quality pada Restoran Sushi Tei di DKI Jakarta, maka berikut adalah kesimpulan yang didapat:

1. Terdapat pengaruh Service terhadap Quality pada Restoran Sushi Tei di DKI Jakarta.
2. Terdapat pengaruh Cleanliness terhadap Quality pada Restoran Sushi Tei di DKI Jakarta.

3. Tidak terdapat pengaruh Organization terhadap Quality pada Restoran Sushi Tei di DKI Jakarta.

Hal tersebut terjadi karena penataan produk dan pemasaran produk tidak memengaruhi kualitas produk yang dirasakan oleh pelanggan. Morano (2018) dalam penelitiannya menyatakan organization yang buruk bukan sesuatu yang dapat dihindari dan tidak memiliki pengaruh terhadap quality.

4. Terdapat pengaruh Healthiness terhadap Quality pada Restoran Sushi Tei di DKI Jakarta.

Rekomendasi bagi penelitian selanjutnya. Berikut ini merupakan beberapa rekomendasi yang diharapkan berguna, yaitu:

1. Menambahkan variabel atau faktor lain yang diperkirakan dapat mempengaruhi Quality.

2. Menambahkan jumlah responden penelitian agar data yang dikumpulkan lebih banyak sehingga akan memberikan hasil yang lebih akurat. 


\section{REFERENCES:}

Anderson, David R., et al. 2014. Statistics for Business and Economics. Canada: Southwestern Cengage learning.

Barber, Nelson dan M. Scarcelli, Joseph et al. 2010. Enhancing the assessment of tangible service quality through the creation of a cleanliness measurement scale. 20(1), 70-88.

Bateman, Thomas S. 2017. Management: Leading and Collaborating in a Competitive World. United States: The McGraw-Hill.

Carillo, E et al. 2012. Why buying functional foods? Understanding spending behavior through structural equation modelling. Food Research International. 50(1), 361-368.

Chang, Yonghwan et al. 2016. The effect of perceived brand leadership on luxury service WOM. Journal of Service Marketing. 30(6), 659-671.

Hair, Joseph F., et al. 2014. Multivariate Data Analysis. England: Pearson Education Limited.

Heizer, Jay. 2017. Operations Management: Sustainability and Supply Chain Management. America States: Pearson education.

Kotler, Philip dan Kevin Lane Keller. 2016. Marketing Management. America States: Pearson education.

Mai, Robert et al. 2016. Light and Pale Colors in Food Packaging: When Does This Package Cue Signal Superior Healthiness or Inferior Tastiness? Journal of Retailing. 92(4), 426-444.

Robbins, Stephen P. dan Coutler, Mary. 2018. Management. America States: Pearson education.

Saha, Arunoday et al. 1989. Human Factors behind the Development of Japanese Product Quality. Institute of Public Enterprise. Vo. 6, No. 1.

Sugiyono. 2016. Metode Penelitian Kuantitatif, Kualitatif, dan R\&D. Bandung: Alfabeta.

Tinoco, Maria Auxiliadora Cannarozzo dan Riberio, José Luis Duarte et al. 2008. Estudo qualitativo dos principais atributos que determinam a percepção de qualidade e de preço dos consumidores de restaurantes a la carte. 15(1), 73-87.

Walsh, John et al. 2014. Business strategies used by Micro-SMEs in a Bangkok street market. Journal of Enterprising Communities: People and Places in the Global Economy. 8(2), 147-158. 